\title{
CLINICAL PERSPECTIVES
}

\section{Benefits and Risks of Menopausal Estrogen and/or Progestin Hormone Use ${ }^{1,2}$}

\author{
Virginia L. Ernster, Ph.D., ${ }^{* 3}$ Trudy L. Bush, Ph.D., $\dagger$ \\ George R. Huggins, M.D. $\ddagger$ Barbara S. Hulka, M.D., M.P.H. ${ }^{\S}$ \\ Jennifer L. Kelsey, Ph.D.," ANd David Schottenfeld, M.D."
}

*Department of Epidemiology and International Health, School of Medicine, University of California, San Francisco, California 94143; +Department of Epidemiology, School of Hygiene and Public Health, Johns Hopkins University, Baltimore, Maryland 21205; $¥$ Department of Obstetrics and Gynecology, Francis Scott Key Medical Center, 4940 Eastern Avenue, Baltimore, Maryland 21224; ${ }^{5}$ Department of Epidemiology, School of Public Health, University of North Carolina, Chapel Hill, North Carolina 27514; "Division of Epidemiology, School of Public Health, Columbia

University, New York, New York 10032; and "Department of Epidemiology, School of Public Health, University of Michigan. Ann Arbor, Michigan 48109

Current evidence is reviewed here on risks and benefits of estrogen and progestin use by peri- and postmenopausal women in relation to the following conditions: endometrial cancer, breast cancer, osteoporosis, and coronary artery disease (CAD). On balance, estrogen therapy appears to be beneficial for menopausal women, as it probably reduces the risks of CAD and osteoporosis, two of the major causes of mortality and morbidity. Although unopposed estrogen therapy increases the risk of endometrial cancer, that cancer is relatively rare and is not fatal in the vast majority of cases associated with estrogen use. Definitive conclusions about the relation of menopausal estrogens to breast cancer cannot be drawn due to inconsistent evidence to date. Although evidence from randomized controlled trials is lacking, biochemical and clinical evidence suggest that progestin supplementation is associated with a reduction in endometrial cancer risk in women taking menopausal estrogens. Progestin supplementation also may augment the beneficial effects of estrogens in providing protection against osteoporosis, although this effect is not yet well established. There is little direct evidence bearing on the relation of menopausal progestins to breast cancer. Although studies of CAD per se are lacking at present, progestins probably unfavorably alter lipoprotein profiles, thereby increasing a user's risk of CAD. Given the relatively high incidence and mortality of CAD in postmenopausal women, any negative effects on CAD risk could potentially counterbalance beneficial effects on other causes. We conclude that estrogen replacement therapy is of potential benefit to postmenopausal women, but that the question of progestin supplementation requires further study, particularly for CAD risk. 1988 Academic Press, Inc.

\section{INTRODUCTION}

Considerable controversy surrounds the use of estrogens and progestins by peri- and postmenopausal women. Some risks and some benefits of menopausal

\footnotetext{
${ }^{1}$ Based on a symposium by the same title held at the 10th Annual Meeting of the American Society of Preventive Oncology, Bethesda, MD, 1986.

${ }^{2}$ Supported in part by USPHS Grant P01 CA 13556-15 from the National Cancer Institute, Bethesda, MD.

${ }^{3}$ To whom reprint requests should be addressed.
} 
hormone use have been clearly established. However, the risk-benefit equation cannot be formulated definitively at present owing to inadequate information in several key areas. This article reviews current evidence, prefaced by a brief discussion of recent trends in the prevalence of menopausal hormone use.

\section{Trends in Prevalence of Menopausal Hormone Use}

In the United States there was a dramatic increase in dispensed retail prescriptions for noncontraceptive estrogens between the mid-1960s and the early 1970 s ( $90 \%$ of noncontraceptive estrogens in 1983 were used by women, and $56 \%$ of the associated diagnoses in women were related to aging, i.e., menopausal symptoms, senile vaginitis, and osteoporosis (66)). After reports of possible association with endometrial carcinoma $(124,154)$, sales of noncontraceptive estrogens dropped in 1976 by almost $30 \%$, with the greatest decline in the high-dose estrogen products. This downward trend continued until 1980. Since then, there have been annual increments in noncontraceptive estrogen prescriptions (66). Estrogen replacement therapy at menopause most commonly consists of conjugated natural estrogens (unlike the synthetic formulations in oral contraceptives). Recently, transdermal estrogen (estradiol) has been prescribed for postmenopausal women (75); however, published reports of its safety and efficacy are too preliminary and will not be considered in this review.

Trends in concomitant prescriptions of Premarin (the conjugated estrogen most frequently prescribed for menopausal women) with Provera (the most frequently prescribed progestin) showed steady increases between 1980 and 1983 (66). Since 1983, the upward trends have continued, with progestin supplementation of estrogen prescriptions becoming increasingly more common (Dianne L. Kennedy, FDA, personal communication). Progestins (or progestogens) include the natural hormone (progesterone) and synthetic derivatives. Menopausal women in the United States receive the synthetic derivatives. Although there are a great many synthetic formulations with widely varying therapeutic effects, the most commonly prescribed forms are the 19-nortestosterone derivatives (e.g., norethindrone) and the hydroxyprogesterone derivatives (e.g., medroxyprogesterone acetate). In the United States in 1983, of all oral noncontraceptive progestin prescriptions, about $11 \%$ were for norethindrone and $89 \%$ for medroxyprogesterone (including Provera). This distribution may not exactly reflect the experience of menopausal women because progestins are given for a number of conditions other than menopausal symptoms.

\section{ESTROGENS}

Estrogen replacement therapy has long been known to protect against the occurrence of such menopausal symptoms as hot flashes and vaginal dryness and itching. The greatest concern about risks associated with menopausal estrogens has focused on endometrial and breast cancers.

\section{Endometrial Cancer: Increased Risk}

For 1987, the American Cancer Society has estimated that there were 2,900 deaths and 35,000 new cases of endometrial cancer in the United States (3). The 
disease generally presents with vaginal bleeding, is usually diagnosed at an early stage, and has a favorable prognosis (i.e., 92\% 5-year relative survival among white women with Stage I disease and $84 \%$ for all stages combined) (95). The average annual age-adjusted incidence rate was higher in 1978-1981 for white (25.1 per 100,000 population) than for black $(13.4$ per 100,000$)(139)$ women.

The magnitude of increase in reported endometrial cancer incidence rates in the late 1960s and early 1970s suggested that a change might have occurred in the nature or frequency of exposure to a causative environmental agent (145). The inference about the likely determinant for this incidence pattern was revealed in 1975 with the publication of two case-control studies showing four- to sevenfold relative risk estimates for the association of estrogen replacement therapy with endometrial cancer $(124,154)$. These reports were followed by a succession of epidemiologic studies that demonstrated elevated relative risks and doseresponse relationships associated with estrogen use (Table 1).

Following the declining trend in estrogen prescriptions during the late 1970s, endometrial cancer incidence rates diminished $(7,143)$. Although the incidence of endometrial cancer increased in the early $1970 \mathrm{~s}$, the concurrent age-adjusted mortality rates remained relatively stable between 1973 and 1981 (95). The stable mortality in the context of rising incidence may be attributed to a general trend toward improving survival in the population and to the fact that a significant proportion of cases among estrogen users were early-stage lesions (26) (Table 2).

Duration of estrogen use and cumulative dose are major predictors of endometrial cancer risk $(6,41,57,58,65,85,90,120,121,129,146)$. One year of use is probably the minimum exposure associated with increased risk $(90,129)$, although some studies have reported an increase in risk only with 3 or more years of use.

Following cessation of use, the period of time after cessation of use required before elevated risks approach those of the nonuser has not been determined precisely. Some studies have described short time intervals of 6 months to 2 years $(57,85)$, whereas one multi-hospital case-control study reported persistently increased risks up to 10 years after cessation of use (121). The data comparing trends of estrogen prescription volume with endometrial cancer incidence rates during the late 1970 s are more consistent with the evidence for a relatively short time interval between cessation and decline in endometrial cancer risk (7).

These epidemiologic data have resulted in important changes in patient management (4). First, lower doses of estrogen, such as the 0.625 -mg daily dosage, are being prescribed, and cyclic therapy is generally recommended, with 1 week of each 4-week cycle to be estrogen-free. Second, progestins are frequently being added during the last 10 days of the estrogen cycle to counteract the proliferative effects of estrogens on the endometrium (see below for the benefits of progestins). Third, physicians are more apt to wean women off hormone therapy after some months or a few years of use to avoid the elevated risks that occur with increasing duration of use. The effort to minimize duration of use runs contrary to the optimal regimen for the prevention of osteoporosis and associated fractures. The potential for causing endometrial cancer may be diminished through careful administration of the minimal therapeutically effective dose of estrogen, in conjunction with cyclical progestins (see below). 


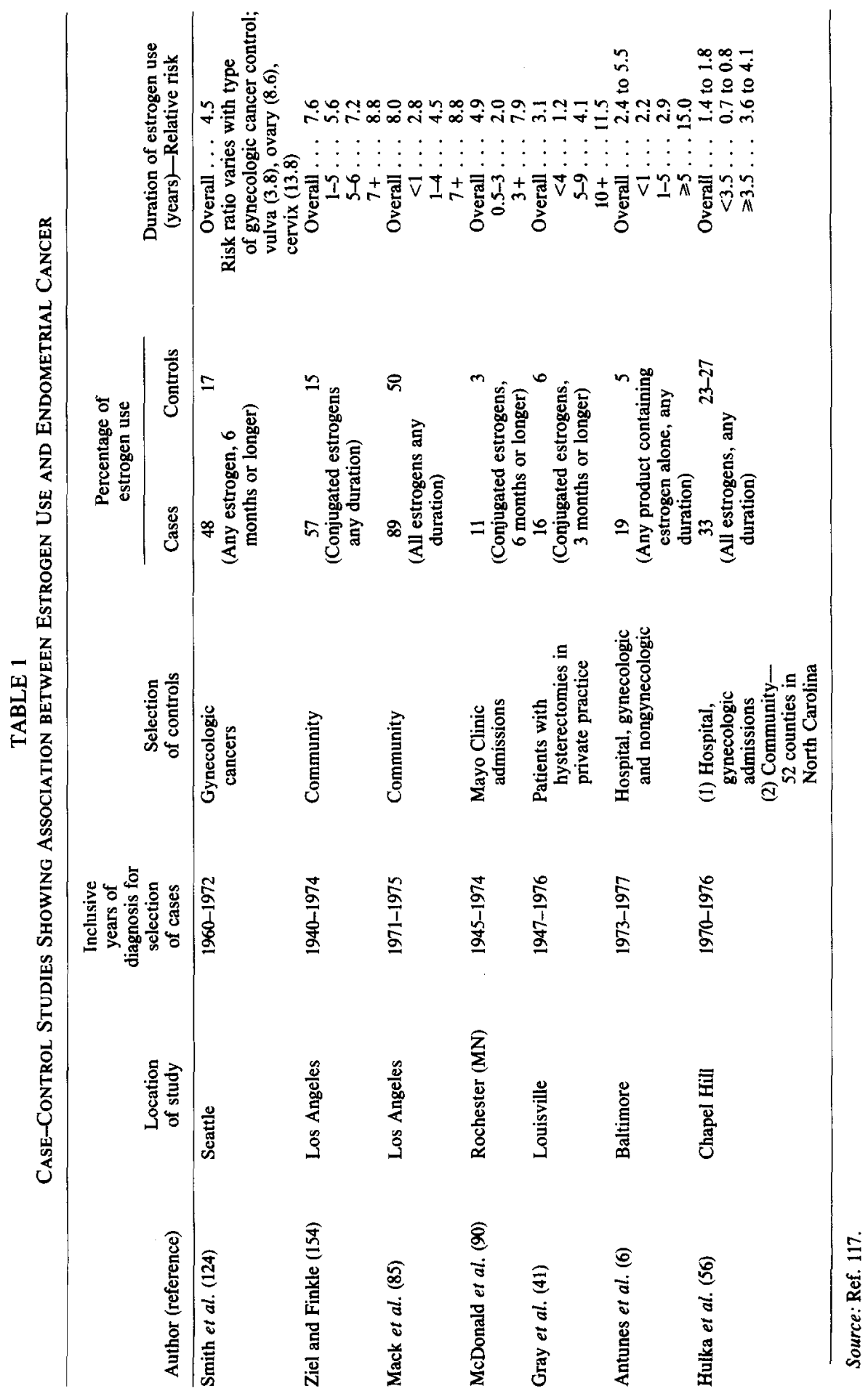


TABLE 2

Age-Adjusted Incidence, Mortality, and Survival for Uterine Corpus Cancer, White Females, United States

\begin{tabular}{|c|c|c|c|c|c|}
\hline Year & $\begin{array}{c}\text { Incidence/ } \\
100,000\end{array}$ & Year & $\begin{array}{c}\text { Mortality/ } \\
100,000\end{array}$ & Year & $\begin{array}{l}5 \text {-Year } \\
\text { relative } \\
\text { survival }\end{array}$ \\
\hline 1969 & 22.6 & & & & \\
\hline 1971 & 24.6 & & & & \\
\hline 1973 & 29.0 & $1973-1977$ & 1.9 & $1970-1973$ & $81 \%$ \\
\hline 1975 & 32.4 & & & & \\
\hline 1977 & 28.5 & & & & \\
\hline $1978-1981$ & 25.1 & $1978-1981$ & 2.1 & 1974-1979 & $87 \%$ \\
\hline
\end{tabular}

Sources: SEER Cancer Incidence and Mortality in the United States, 1973-1981, and "Cancer Rates and Risks," 3rd ed. National Institutes of Health, Bethesda, MD, 1985.

\section{Breast Cancer: Inconsistent Evidence}

In Western Europe and North America, breast cancer represents the most frequent cancer in women, excluding the incidence of nonmelanoma skin cancers. In these countries, breast cancer accounts for about $4 \%$ of all deaths, $20 \%$ of all cancer deaths, and $25 \%$ of all cancer cases in women. For 1987, the American Cancer Society cstimated that there were 130,000 new cases and 40,900 deaths from breast cancer (3).

As the evidence for a causal relationship of noncontraceptive estrogen replacement therapy with endometrial cancer became apparent, there was increased interest in determining a potentially similar relationship of estrogens and breast cancer. The assumption seemed reasonable because of estrogen receptor activity and estrogen dependency in both target organs and because both cancers seem estrogen dependent. Moreover, endometrial and breast cancers share some hormonally related risk factors (e.g., nulliparity).

The case-control studies of breast cancer published before 1980 that had specifically considered estrogen use were uniformly negative (55). Two cohort studies suggested an association; one, in particular, showed an increased risk among exposed women only after 10 years of follow-up (51).

Since 1980, several case-control studies have been reported $(9,48,50,56,62$, $64,115,151$ ), and at least one prospective study (37) has appeared in various versions in several journals. That study purported to show a reduced breast cancer risk among estrogen-exposed women compared with those not exposed.

Ten case-control studies published since 1980 are summarized in Table 3. Some were population-based, while others relied on hospitalized control groups. Many geographic areas within the United States and elsewhere were represented. Most provided analyses separately for pre- and postmenopausal women and for natural versus surgical menopause; one was limited to women under age $55(150,151)$. Most authors chose to examine data separately for women who had had bilateral oophorectomy from those who had undergone a natural menopause, which is appropriate in that the two groups differ with respect to their risk of breast cancer and endogenous estrogen levels. The accumulated knowledge from these studies is inconsistent and controversial. Hoover et al. (50) and La Vecchia et al. (76) 
ERNSTER ET AL.

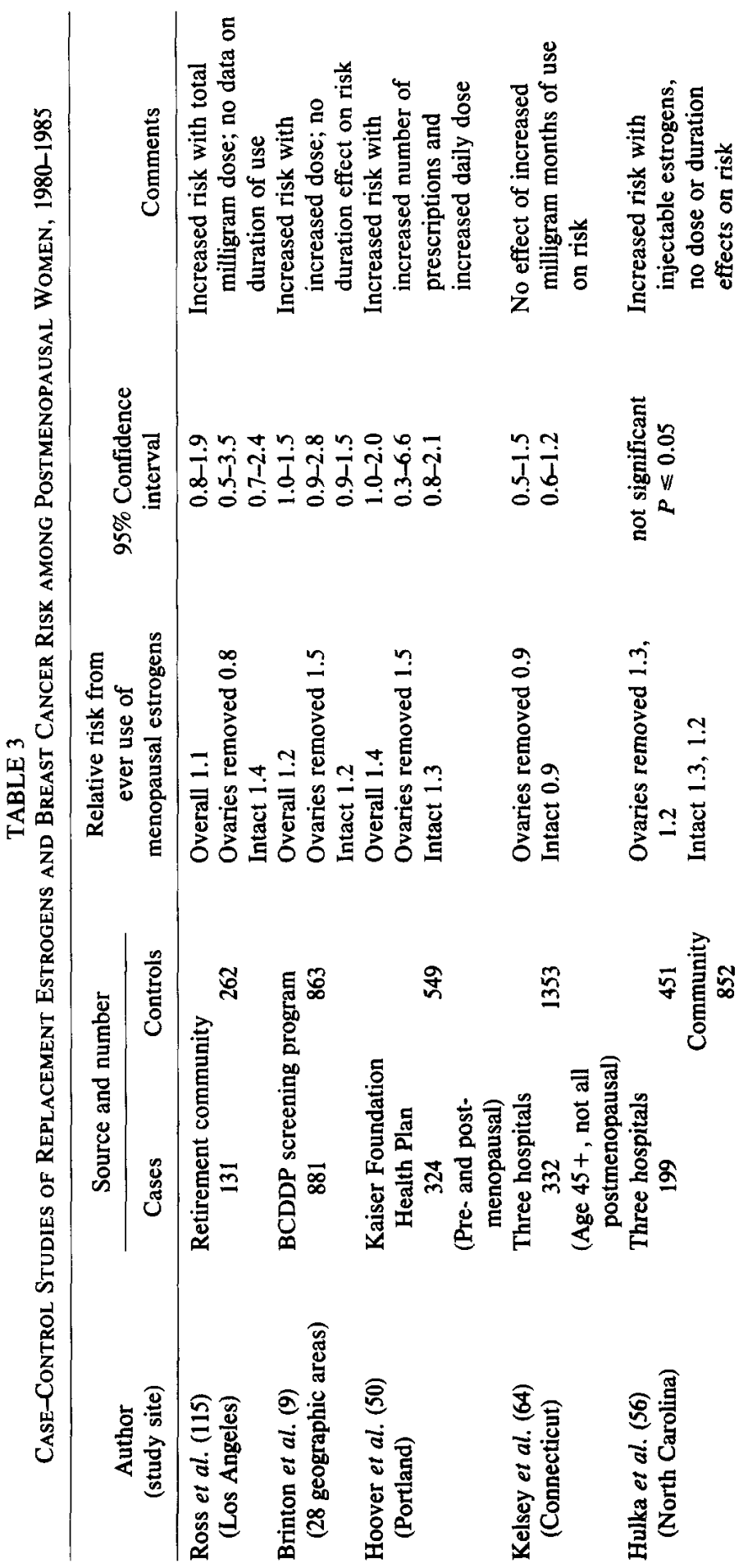




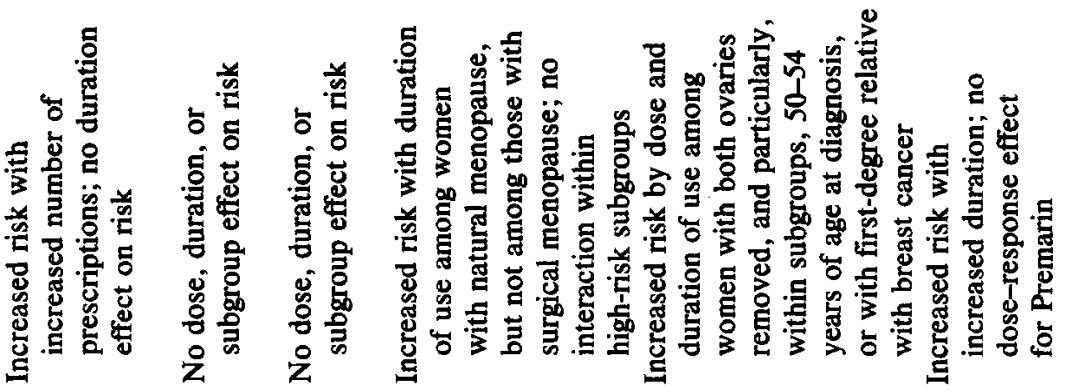

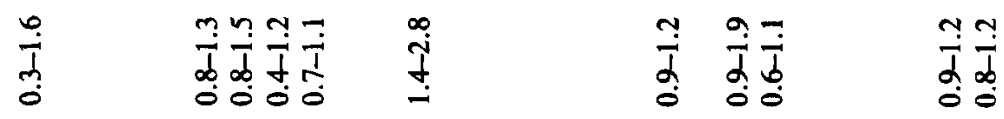

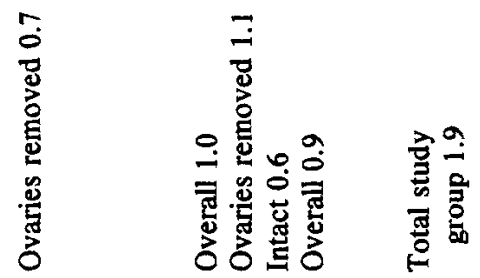
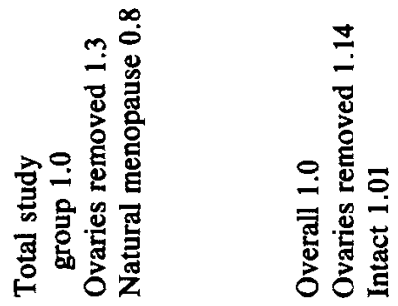

9 ఏํㅀㅀ

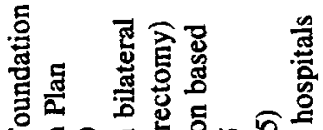

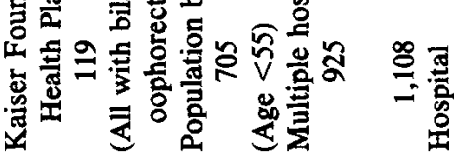

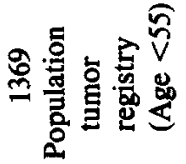

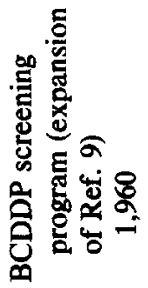

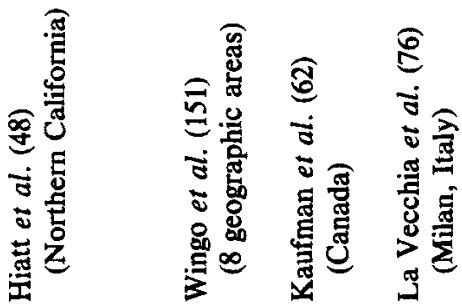

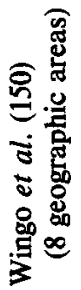

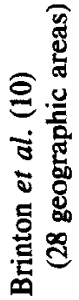


noted an increased risk for breast cancer associated with estrogen use, whereas Kelsey (64), Hulka (56), Hiatt (48), Wingo (150, 151), Kaufman (62), and their respective coauthors reported no elevation in risk. Ross et al. (115) showed an increased breast cancer risk for women who had undergone a natural menopause. Brinton $e t$ al. originally suggested that increased risk occurred primarily among those whose menopause occurred as a result of bilateral oophorectomy (9), but based on a later analysis (10) of their expanded case-control data, the authors found no significant elevations in risk associated with ever use of menopausal hormones in any of the menopause groups studied (natural, ovaries retained, and ovaries removed). As noted below, however, they did find an elevation in risk associated with long-term use.

In most studies, protracted estrogen use did not show the risk enhancement that was observed with endometrial cancer. None of these studies summarized in Table 3 reported a significant duration effect, with the exception of the expanded analysis of Brinton et al. (10) which showed an increase in risk with use duration across the menopausal groups studied; use of menopausal estrogens for 20 or more years was associated with a $50 \%$ increase in risk. The suggestion of a dose effect appears, however, in several of the studies. Ross et al. (115) demonstrated increasing risk with increasing doses. Hoover et al. (50) and Hiatt et al. (48), whose data on estrogen use were based on medical records, showed increased relative risks with increased number of prescriptions, a proxy indicator for intensity of estrogen use. Hulka et al. (56) found an increased risk with injectable estrogen; parenteral administration delivers high circulating levels of biologically active doses to the target organs, because it bypasses the enterohepatic circulation and hepatic deactivation. Brinton et al. reported an increased risk of breast cancer with increasing estrogen dose in their original analysis (9), but this was not confirmed in their expanded analysis (10). Kelsey et al. (64) found no association of breast cancer and milligram-months of estrogen use; nor was an association demonstrated in the Wingo et al. (151) and Kaufman et al. (62) studies that assessed estrogen dosages. The finding of a dose-response relationship in some studies is noteworthy and would be supportive of a causal association, although the negative studies suggest caution in such an interpretation.

Additional important risk factors for breast cancer are benign breast disease, in particular the subgroups with proliferative and atypical cell patterns, and family history of breast cancer. These factors generally weigh heavily with clinicians in decisions about prescribing estrogens. Epidemiologic studies, unless specifically designed to test the potential interactions of estrogens with one or another of these risk factors, usually contain insufficient numbers of subjects to produce reliable estimates of risk. Some authors $(9,10,115,136)$ have suggested that estrogens enhance breast cancer risk in women with prior benign breast disease, but two studies with the largest number of relevant subjects have shown no such association $(62,151)$. A similar equivocal statement could be made about the possible modifying effect of family history $(9,56)$.

In summary, epidemiologic studies have not consistently demonstrated a causal link between estrogen replacement therapy and breast cancer risk. To the extent that such an association exists, it has been observed primarily with high-dosage estrogen, higher than the $0.625 \mathrm{mg}$ of conjugated estrogens that is usually pre- 
scribed daily to relieve menopausal complaints and retard development of osteoporosis. However, even a high-dose effect was not observed in several large, well-designed epidemiologic studies that had sufficient power to detect an association if one existed.

\section{Osteoporosis and Associated Fractures: Beneficial Effect}

A role for estrogen in the etiology of osteoporosis has been suggested by the many studies showing that loss of bone mass accelerates in women just after bilateral oophorectomy or natural menopause $(21,23,54,71,88,96)$ and by the finding that bilateral oophorectomy without estrogen replacement before natural menopause is associated with an increased risk for hip fracture (70).

Many studies have also shown that estrogen replacement therapy at doses of at least $0.625 \mathrm{mg}$ conjugated estrogen or $1.5 \mu \mathrm{g}$ ethinylestradiol per day prevents or greatly retards bone loss in peri- and postmenopausal women as long as estrogen is being taken $(23,24,32,38,52,53,79,93,107,126)$. Doses below these levels afford partial protection $(38,53)$. Following cessation of estrogen use, bone loss occurs at a rate similar to that seen immediately after the menopause in women not treated $(25,82)$. Results from a randomized trial of an estrogen/progestogen treatment versus a placebo in 94 women who were 6 months to 3 years postmenopausal are shown in Fig. 1 (24). After 2 years of estrogen/progestogen use, some of the women were randomly switched from placebo to treatment and others from treatment to placebo. The preservation of bone mass while on estrogen/ progestogen treatment was noted both among those initially assigned to the treatment and among those who started treatment after 2 years. Similarly, the loss of bone mass while on placebo was seen among those initially assigned to placebo and among those assigned to placebo after 2 years on treatment (Fig. 1).

Estrogen replacement therapy also protects against fractures associated with osteoporosis. Several case-control studies $(59,61,71,100,147)$ have reported that estrogen replacement therapy by peri- or postmenopausal women reduces the

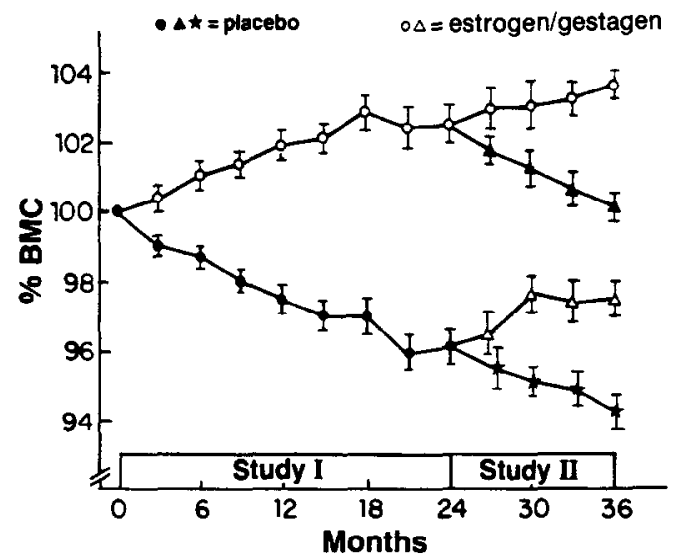

FIG. 1. Bone mineral content (BMC) of the distal forearm as a function of time and treatment in 94 (Study I) and 77 (Study II) women soon after menopause (24). 
risk for hip and Colles' fractures by about $50 \%$ while the estrogens are being taken. The two case-control studies $(100,147)$ that considered the effect of dose showed no difference in the degree of protection according to dose. Table 4 shows that, in general, the longer the use, the lower the risk-at least through 6 years of use. Some evidence (147) suggests that much of the protective effect is lost within a few years of stopping estrogen therapy. Replacement estrogens also reduce the risk of vertebral fractures $(32,39,81,109)$.

Thus, studies consistently show that estrogen replacement therapy protects against osteoporosis and associated fractures while the estrogens are being taken. However, several details of the relationship remain to be elucidated. First, since bone loss appears to accelerate around the time of menopause, some would argue that the shorter the interval between onset of menopause and initiation of estrogen use, the more bone mass is preserved (2). Two case-control studies of hip fracture $(59,70)$, in fact, suggest that use close to the time of menopause affords greater protection than the same extent of use in later years. However, if bone loss accelerates immediately after cessation of use to an extent similar to that immediately following menopause $(25,82)$, this argument for the importance of starting estrogen therapy immediately after the menopause is not compelling, unless estrogens are to be taken indefinitely. Studies of the extent to which estrogens started several years after menopause retard bone mass loss are needed. Second, the optimal dose of estrogen for maximum benefit is uncertain; evidence is contradictory as to whether doses greater than $0.625 \mathrm{mg}$ of conjugated estrogens or $1.5 \mu \mathrm{g}$ of ethinylestradiol bring about a further increase in cortical bone mass or decrease in fracture risk $(23,38,52,53,79,93,100,104,147)$. Third, whether the addition of cyclic progestogen to the estrogens is more beneficial than estrogens alone, as suggested by short-term trials $(24,25)$, remains to be determined in long-term trials. Effects of progestogens will be discussed in greater detail below. Fourth, the finding of Weiss et al. (147) that the protective effect of estrogen replacement therapy against hip and forearm fractures is lost within a few years after cessation of use needs to be evaluated in other studies, since (as Weiss et al. point out) numbers of former users were small in their studies. Also, one would expect that prevention or retardation of bone loss, even temporarily, would result in greater ultimate preservation of bone mass than if loss had continued unabated.

TABLE 4

Relative Risk of Fracture of the Hip or Lower Forearm According to Duration of Use of PostMenopausal Estrogen

\begin{tabular}{lc}
$\begin{array}{c}\text { Duration of use } \\
\text { (years) }\end{array}$ & Relative risk \\
\hline No use or <1 year & 1.0 \\
$1-2$ & 0.8 \\
$3-5$ & 0.9 \\
$6-9$ & 0.4 \\
$>10$ & 0.5 \\
\hline
\end{tabular}

Source: Ref. 147. 


\section{Coronary Artery Disease: Probable Beneficial Effect}

Cardiovascular diseases (CVDs) are by far the leading cause of death among U.S. women as well as men (140). Thus, even minor changes in CVD risk as a result of estrogen replacement therapy could affect life expectancy in large numbers of women, easily outweighing the effects of changes in risk of other, lesscommon diseases. Most studies report that estrogen replacement therapy protects against CVD and, in particular, against coronary artery disease (CAD) among women (Table 5). Of 19 studies, 15 show a reduction in risk among estrogen users $(1,13,20,45,47,73,86,94,102,103,105,116,131,133,134)$; two studies show no effect $(113,114)$, and two report an increased risk $(60,149)$.

In the studies showing a protective effect, the estimated relative risk in estrogen users compared with nonusers varies from about 0.2 to 0.7 . Of the two reports showing no effect of estrogen use on CVD risk, one (114) was of women under 50 years of age, who-because of their young age-had experienced infrequent use of estrogen replacement therapy and were at minimal risk for CVD. Only a small, flawed case-control study (60) and the Framingham Study (149) have reported an increased risk for CVD among estrogen users (Relative risk $[R R]=8.44$ and 1.76, respectively). The case-control study suffered from various methodologic problems (14), and a reanalysis (30) of the Framingham data using more specific

TABLE 5

Studies of Estrogen Replacement Therapy and Cardiovascular Disease

\begin{tabular}{|c|c|c|c|c|c|}
\hline Study & Design & Endpoint $^{a}$ & $\begin{array}{l}\text { Relative } \\
\text { risk }\end{array}$ & $\begin{array}{c}95 \% \\
\text { Confidence } \\
\text { limits }\end{array}$ & $P$ \\
\hline Lafferty et al. (73) & Cohort & MI & 0.16 & $b$ & 0.051 \\
\hline MacMahon (86) & Cohort & All CVD & 0.30 & $b$ & $\boldsymbol{c}$ \\
\hline Stampfer et al. (131) & Cohort & All CVD & 0.30 & $0.2-0.6$ & 0.001 \\
\hline Nachtigall et al. (94) & Trial & MI & 0.33 & $b$ & 0.240 \\
\hline Hammond et al. (45) & Cohort & All CVD & 0.33 & $b$ & 0.001 \\
\hline Potocki (105) & Cohort & All CVD & 0.33 & $b$ & c \\
\hline Bush et al. $(15,16)$ & Cohort & CVD deaths & 0.34 & $0.1-0.9$ & 0.023 \\
\hline Talbott et al. (134) & Case-Control & Sudden death & 0.34 & $0.1-3.2$ & c \\
\hline Burch et al. (13) & Cohort & Fatal CAD & 0.43 & $0.2-0.7$ & $c$ \\
\hline Ross et al. (116) & Case-Control & Fatal CAD & 0.43 & $b$ & 0.010 \\
\hline Petitti et al. (102) & Cohort & CVD deaths & 0.50 & $0.2-0.9$ & $c$ \\
\hline Henderson et al. (47) & Cohort & MI & 0.54 & $b$ & 0.007 \\
\hline Szklo et al. (133) & Case-Control & Nonfatal MI & 0.61 & $0.2-1.9$ & $c$ \\
\hline Adam et al. (1) & Case-Control & Fatal MI & 0.65 & $0.5-0.9$ & $c$ \\
\hline Pfeffer et al. (103) & Case-Control & MI & 0.68 & $0.3-1.4$ & 0.300 \\
\hline Rosenberg et al. (113) & Case-Control & Nonfatal MI & 0.97 & $0.5-2.0$ & $c$ \\
\hline Rosenberg et al. (114) & Case-Control & Nonfatal MI & 1.00 & $0.6-1.7$ & c \\
\hline Wilson et al. (149) & Cohort & All CVD & 1.76 & $b$ & 0.010 \\
\hline Jick et al. (60) & Case-Control & Nonfatal MI & 8.44 & $4.6-12.3$ & 0.002 \\
\hline
\end{tabular}

${ }^{a}$ MI, myocardial infarction; CVD, cardiovascular disease; CAD, coronary artery disease.

${ }^{b}$ Relative risk cannot be computed from available published data.

${ }^{c} \boldsymbol{P}$ value not given. 
endpoints showed a protective effect of estrogen use among women 50-59 years $(R R=0.32)$, and no adverse effects among women 60 years and older $(R R=1.1)$.

Data on estrogen dose, duration of use, and type of estrogen used in relationship to CAD are generally unavailable in the published reports. Thus, it is unclear whether dose and length of use affect risk. However, some reports showed that women currently using estrogens had a lower risk of CAD than women who had previously used them $(93,116,131)$. Effects of recency of use, dose, length of use, age at time of use, and type of compound used are important issues meriting further study.

It is biologically plausible that estrogen replacement therapy protects against the development of CAD. Serum high-density lipoprotein (HDL) is a strong, inverse predictor of CAD, and estrogen use has been shown to raise serum levels of HDL $(18,111,144)$. In one report $(17)$, women using moderate doses $(0.625 \mathrm{mg})$ of oral conjugated estrogens had HDL levels approximately $17 \%$ higher than women not taking estrogens. Theoretically, this magnitude of increase in HDL levels would correspond to about a $40 \%$ reduction in CVD risk.

Oral estrogens tend to reduce low-density lipoprotein (LDL), the atherogenic subfraction of total cholesterol. In the study (17) cited above, estrogen users had LDL levels approximately $7 \%$ lower than those of nonusers. Such difference in LDL levels would theoretically correspond to about a $3 \%$ reduction in CVD risk among women.

\section{PROGESTINS}

To date, relatively few studies of the long-term health effects of menopausal progestational agents have been undertaken. Clinical and biochemical evidence would suggest that progestins counter the adverse effects of estrogens on the endometrium. The published studies of the relation of progestins to breast cancer risk do not permit conclusions to be drawn at this time. Indeed, long-term use, namely for about 2 years or longer, of combination oral contraceptives with relatively high progestin content (i.e., formulations with the equivalent of $2.5 \mathrm{mg}$ or more of norethindrone acetate) reduces the risk of benign breast disease about 50 to $60 \%(130)$. As reviewed below, some evidence suggests that progestins given alone can prevent or arrest bone loss, similar to estrogens, and that cyclic progesterone coupled with estrogen may further increase bone mass, at least in the short term. Considerable concern has been voiced over the potential adverse effects of progestins on CVD, mediated by unfavorable changes in lipoprotein fractions associated with progestin use.

\section{Endometrial Cancer: Beneficial Effect of Progestin in Women}

Taking Estrogens

Estrogen is a growth hormone for endometrial tissue. During the first half of a normal menstrual cycle (proliferative phase), estrogen activates special intracytoplasmic proteins in the endometrial cells. These special proteins or receptors bind estrogen with a high affinity. Each endometrial cell may contain 5,000 to 15,000 of these receptors. The activated estrogen receptor complex stimulates new cell proliferation. Synthesis of progesterone receptors in endometrial cells is 
largely dependent on estrogen stimulation. Without the prior estrogen priming, progesterone has little activity on endometrial cells. Progesterone also inhibits estrogen receptor activity as well as the synthesis of progesterone binding sites $(5$, $40,46,69,89$ ).

Without the addition of progesterone and conversion from proliferative to secretory pattern, the endometrium has a tendency to shed in an irregular and unpredictable fashion. Continued unopposed estrogen stimulation produces the histologic pattern of hyperplasia, which has been shown to advance to adenomatous hyperplasia, carcinoma in situ, or eventually to endometrial cancer (12, $34,42,44,84,101)$. This progression is well recognized in patients with SteinLeventhal syndrome (125) and patients with estrogen-producing tumors (43). An elevated risk for endometrial cancer has also been reported in infertile women with disorders characterized by unopposed estrogen production (112). The daily addition of potent synthetic progestogens to the estrogen-primed endometrium produces a markedly altered endometrial response (135). This type of endometrium has a decidual pattern with a tendency to atrophy rather than progress to hyperplasia.

The ability of potent progestogens to produce progressive endometrial atrophy has led to their use as therapeutic agents $(67,68,148)$. In addition to their ability to convert adenomatous hyperplasia to normal endometrium, pharmacologic doses of progestogens may be used to treat metastatic adenocarcinoma of the endometrium; this will produce objective regression of the lesions in approximately $30 \%$ of patients $(33,108)$.

Although the evidence for a protective effect of cyclical progestogens in reducing the risk for endometrial neoplasia is compelling, no firm conclusions regarding the most effective progestogen and dosage regimen can be drawn. One commonly suggested regimen is $10 \mathrm{mg}$ of medroxyprogesterone acetate orally for the last 10 days of each cycle. When this progestogen is prescribed in peri- and postmenopausal women 50-60 ycars of age receiving $0.625 \mathrm{mg}$ conjugated estrogens orally, 97\% will experience a 3- to 4-day "menstrual flow." This proportion decreases with increasing age so that by age $65,60 \%$ continue to experience light bleeding (36). This persistent bleeding during the sixth and seventh decades of life is objectionable to some women, making compliance a potential problem even among women who may appreciate the therapeutic benefits of this regimen. With estrogen alone, however, the bleeding is less predictable and therefore also potentially problematic.

\section{Breast Cancer: An Open Question}

Several lines of epidemiologic evidence suggest a protective effect of progestin for breast cancer. Women with a history of infertility due to endogenous progesterone deficiency were at increased risk of premenopausal (not postmenopausal) breast cancer compared with women whose infertility was due to nonhormonal causes in one study (27), and women with infertility due to conditions causing unopposed estrogen production were found to have a nonsignificant excess of breast cancer compared to women in the general population in another study (112). In addition, breast cancer risk has been reported to be inversely related to 
plasma progesterone levels $(92,118)$. The preliminary results of an international study showed that progestins administered as injectable contraceptives (depot medroxyprogesterone acetate) were associated with a decreased breast cancer risk (152). Finally, in a nested case-control study, risk for benign breast disease was shown to be inversely related to progesterone dose in oral contraceptives (11).

On the other hand, conflicting evidence is derived from several sources. Epidemiologic investigations have failed to find any evidence of differences in menstrual cycle irregularity among women with breast cancer compared with controls (122) nor differences in luteal phase progesterone levels in women with a history of benign breast disease or breast cancer compared with healthy premenopausal parous women (106). A study that followed 5,000 women receiving injections of medroxyprogesterone for contraception for 4 to 13 years did not exhibit any alteration in breast cancer risk (78). Moreover, the large-scale Contraceptive and Steroid Hormone (CASH) study found no relation of progestogen "potency" of oral contraceptives to breast cancer (130), following an earlier report that breast cancer risk was positively related to the progestin "potency" of oral contraceptives $(104,132)$.

One widely reported prospective study $(35,37)$ suggested that women taking postmenopausal estrogen with progestin had a markedly reduced risk for breast cancer compared with women taking estrogens alone or untreated women. The study has been criticized for failure to describe and adjust for important differences among women in the various treatment groups $(31,77)$. Since it was not a randomized study, women whom physicians chose to treat with progestins may have differed from other women with regard to family and personal history of breast disease and other breast cancer risk factors. A small clinical trial by Nachtigall et al. (94) also showed lower breast cancer incidence among women receiving high-dose conjugated estrogens cyclically with progesterone $(0 / 84)$, when compared with control women (4/84).

Although some data on endogenous progestins and on exogenous progestins in oral contraceptives support the notion that progestins may play a protective role, the evidence is not consistent, and there are no carefully designed, large-scale studies of the potential causal role of exogenous menopausal progestins in breast cancer. At present the evidence would at least suggest that the addition of cyclical progestins to menopausal estrogens will have no adverse affects on breast cancer risk.

\section{Osteoporosis and Associated Fractures: Probable Beneficial Effect}

The few available studies of the role of progestins in osteoporosis have been based upon limited sample size, and none have addressed the question of longterm effects. On balance, however, they suggest a beneficial effect. Some evidence indicates that progestins given alone confer protection against osteoporosis $(29,83,119)$, and that combined estrogen/progestin regimens have a greater effect than estrogen alone by promoting new bone formation $(24,25,28,93,110)$. There is no evidence that adding progestins to estrogens negates the beneficial effects of 
estrogen given alone. More research is needed of possible differential effects on bone matrix and mineralization by type of progestin administered (80).

\section{Coronary Artery Disease: Potential Increased Risk}

The effects of progestins on risk of CAD may be the unrcsolved issue of greatest potential importance in the menopausal replacement hormone risk-benefit equation. The issue is unresolved because studies of the relationship of menopausal hormones to CAD have been largely limited to unopposed estrogens and have not evaluated the effect of progestin supplementation. However, women who take oral contraceptives that contain relatively high doses of the progestins norethindrone acetate and norgestrel have been reported to be at increased risk for myocardial infarction or stroke compared with women who take lower dose formulations $(63,91)$.

Serum lipoproteins, a major predictor of CVD risk, appear to be adversely affected by progestins. A variety of studies have shown that progestins are associated with increases in LDL and decreases in HDL. Such effects have been reported for unopposed progestins, for progestins combined with estrogens in various formulations of oral contraceptives $(8,142)$, and for progestins given to postmenopausal women as a supplement to estrogen replacement therapy $(74,99$, 142); the extent of change in lipoproteins was dependent on the type of progestin administered. The vast majority of progestins prescribed for menopausal women are either medroxyprogesterone acetate (Provera), a 17 $\alpha$-hydroxyprogesterone derivative, or the 19-nortestosterone derivatives, mainly norgestrel and norethisterone. Unopposed 19-nor derivatives decrease HDL cholesterol levels substantially, and modestly increase LDL cholesterol levels $(72,123,143)$. Although some studies suggest that medroxyprogesterone acetate taken alone may decrease HDL cholesterol levels $(123,138)$, other investigators have concluded that use of this progestin does not result in the adverse lipoprotein profiles associated with the 19-nor derivatives $(127,128)$. When the 19-nor agents are added to estrogens, HDL levels are reduced below baseline, i.e., levels are lower than those in women not receiving estrogens $(49,87,98,153)$. When medroxyprogesterone acetate is added to estrogens, the HDL levels approach those of women not receiving estrogens $(97,98,141)$. One study, however, showed similar reductions in HDL associated with both levonorgestrel, a 19-nor agent, and medroxyprogesterone acetate (99). A randomized clinical trial of women receiving the progestin norethisterone acetate with estrogens and women on placebo found no differences in serum HDL cholesterol levels, which the authors suggested might be explained by the much lower progestin dose in their study (1 mg/day for 10 days) compared with previous investigations (22). Still, the favorable increase in HDL cholesterol usually seen with estrogens given alone was not observed.

Taken together, the above findings have led some investigators to conclude that progestin doses should be kept to the minimum possible to reduce endometrial cancer risk associated with unopposed estrogen use, or that they be avoided, especially among women who have had a hysterectomy (18) or those who have significant hyperlipidemia (137). Whether the adverse changes in lipoprotein levels associated with progestin use translate into an increased risk for $\mathrm{CAD}$, and 
whether that risk is sufficient to outweigh any benefits that accrue by adding progestins to menopausal estrogen therapy are areas that require careful study.

\section{SUMMARY}

On balance, for the diseases considered here, estrogen therapy appears to be beneficial for menopausal women, as it probably reduces the risks for CAD and osteoporosis, two of the major causes of mortality and morbidity among postmenopausal women. Although unopposed estrogen therapy increases risk for endometrial cancer, that cancer is relatively rare and is not fatal in the vast majority of cases associated with estrogen use. Definitive conclusions about the relation of menopausal estrogens to breast cancer cannot be drawn. The evidence is inconsistent, and if there is any increase in risk associated with use, it is likely to be small and to apply only to use of high-dose preparations $(>0.625 \mathrm{mg})$. For the most part, the higher-dose preparations should not be necessary for clinical relief of menopausal symptoms, to favorably affect CAD risk, or for prevention of osteoporosis.

There is considerably less consensus on the issue of menopausal progestins. Although evidence from randomized controlled trials is lacking, biochemical and clinical evidence suggests that progestin supplementation is associated with a reduction in endometrial cancer risk among women taking menopausal replacement estrogens. Progestins may augment the beneficial effects of estrogens in providing protection against osteoporosis, although this effect is far from certain at this time. For breast cancer, there is little direct evidence bearing on either a causal or protective role of menopausal progestins.

However, progestins probably unfavorably alter the lipoprotein profile, which may increase a user's risk for CAD, although studies of CAD outcomes are lacking at present. Without knowing the effect of progestin supplementation on CAD, it would be inappropriate to draw any firm conclusions regarding its adoption at this time. Given the relatively high incidence and mortality of CAD in postmenopausal women, even a minor increase in risk, or negation of the benefits associated with unopposed estrogens, would not only cancel but also dramatically outweigh the "benefits" of progestins for other much less common diseases, most notably endometrial cancer. In terms of absolute numbers of lives affected, any negative effects on CAD risk could potentially counterbalance or displace the beneficial effects on all other causes combined.

We conclude that moderate-dose estrogen replacement therapy is of potential benefit to postmenopausal women, but that progestin supplementation requires further study, particularly for CAD risk, before conclusions regarding its use can be drawn. Caution would dictate that if progestins are prescribed, the lowest doses possible to achieve desired effects on the endometrium should be used, with preference given to medroxyprogesterone acetate over the 19-nor steroidal agents. Recommendations for individual patients may vary depending on their risk characteristics, including, among others, family history, lipid profiles, and hysterectomy status. Since there is wide variation in biologic activity among the various progestational agents, future studies should examine the effects on disease by type of progestin, dose, and route of administration. 


\section{ACKNOWLEDGMENT}

We thank Maureen Morris for her valuable assistance.

\section{REFERENCES}

1. Adam, S., Williams, V., and Vessey, M. P. Cardiovascular disease and hormone replacement treatment: A pilot case-control study. Brit. Med. J. 282, 1277-1278 (1981).

2. Aitken, J. M., Hart, D. M., and Lindsay, R. Oestrogen replacement therapy for prevention of osteoporosis after oophorectomy. Brit. Med.J. 2, 515-518 (1973).

3. American Cancer Society. Cancer statistics, 1986. Ca. Cancer J. Clin. 37, 12-13 (1987).

4. American College of Obstetricians and Gynecologists. "Estrogen Replacement Therapy." ACOG Technical Bulletin 93, April 1986.

5. Anderson, J. N., Peck, E. J., and Clark, J. H. Estrogen-induced uterine responses and growth: Relationship to receptor estrogen binding by uterine nuclei. Endocrinology 96, 160-167 (1975).

6. Antunes, C. M. F., Stolley, P. D., Rosenshein, N. B., and Davies, J. L. Endometrial cancer and estrogen use. Report of a large case-control study. New Engl. J. Med. 300, 9-13 (1979).

7. Austin, D. F., and Roe, K. M. The decreasing incidence of endometrial cancer: Public health implications. Amer. J. Public Health 72, 65-68 (1982).

8. Bradley, D. D., Wingerd, J., Petitti, D. B., Krauss, R. M., and Ramcharan, S. Serum highdensity-lipoprotein cholesterol in women using oral contraceptives, estrogens and progestins. New Engl. J. Med. 299, 17-20 (1978).

9. Brinton, L. A., Hoover, R. N., and Fraumeni, J. F. Menopausal estrogen use and risk of breast cancer. Cancer 47, 2517-2522 (1981).

10. Brinton, L. A., Hoover, R. N., and Fraumeni, J. F. Menopausal oestrogens and breast cancer risk: An expanded case-control study. Brit. J. Cancer 54, 825-832 (1986).

11. Brinton, L. A., Vessey, M. P., Flavel, R., and Yeates, D. Risk factors for benign breast disease. Amer. J. Epidemiol. 113, 203-214 (1981).

12. Bromberg, Y. M., Liban, E., and Laufer, A. Early endometrial carcinoma following prolonged estrogen administration in an ovariectomized woman. Obstet. Gynecol. 14, 221-226 (1959).

13. Burch, J. C., Byrd, B. F., Jr., and Vaughn, W. K. The effects of long-term estrogen on hysterectomized women. Amer. J. Obstet. Gynecol. 118, 778-782 (1974).

14. Bush, T. L., and Barrett-Connor, E. Noncontraceptive estrogen use and cardiovascular disease. Epidemiol. Rev. 7, 80-104 (1985).

15. Bush, T. L., Barrett-Connor, E., Cowan, L. D., Criqui, M. H., Wallace, R. B., Suchindram, C. M., Tyroler, H. A., and Rifkind, B. M. Cardiovascular mortality and non-contraceptive use of estrogen in women: Results from the Lipid Research Clinics Program Follow-Up Study. Circulation 75, 1102-1109 (1987).

16. Bush, T., Cowan, L., Barrett-Connor, E., Criqui, M., Karon, J., Wallace, R., Tyroler, H., and Rifkind, B. Estrogen use and cardiovascular mortality: The Lipid Research Clinics Follow-up Study. Amer. J. Epidemiol. 118, 450 (1983). (Abstract)

17. Bush, T., Criqui, M., Cowan, L., Barrett-Connor, E., Wallace, R., Tyroler, H. A., Suchindram, C. M., Cohn, R., and Rifkind, B. M. Cardiovascular disease mortality in women: Results from the Lipid Research Clinics Follow-Up Study, in "Coronary Heart Disease in Women" (E. Eaker, B. Packard, N. Wenger, T. Clarkson, H. A. Tyroler, Eds.) Haymarket Doyle, New York, 1987.

18. Bush, T., and Miller, V. Effects of pharmacologic agents used during menopause: Impact on lipids and lipoproteins, in "Menopause: Physiology and Pharmacology" (D. Mishell, Ed), pp. 121-136. Year Book Medical Publications, Chicago, 1987.

19. Byrd, B. F., Burch, J. C., and Vaughn, W. K. The impact of long-term estrogen support after hysterectomy. Ann. Surg. 185, 574-580 (1977).

20. Campbell, P. E., and Barter, G. A. The significance of atypical hyperplasia. J. Obstet. Gynaecol. Brit. Commonw. 68, 688-692 (1961).

21. Cann, C. E., Genant, H. K., Ettinger, B., and Gordon, G. S. Spinal mineral loss in oophorectomized women. JAMA 244, 2056-2059 (1980).

22. Christiansen, C., Christensen, M. S., Grande, P., and Transbl, I. Low-risk lipoprotein pattern 
in post-menopausal women on sequential oestrogen/progestogen treatment. Maturitas 5, 193 199 (1984).

23. Christiansen, C., Christensen, M. S., McNair, P., Hagen, C., Stocklund, K.-E., and Transbl, I. Prevention of early postmenopausal bone loss: Controlled 2-year study in 315 normal females. Eur. J. Clin. Invest. 10, 273-279 (1980).

24. Christiansen, C., Christensen, M. S., and Transbl, I. Bone mass in postmenopausal women after withdrawal of oestrogen/gestagen replacement therapy. Lancet 1, 459-461 (1981).

25. Christiansen, C., Riis, B. J., Nilas, L., Bodbro, P., and Deftas, L. Uncoupling of bone formation and resorption by combined oestrogen and progestagen therapy in postmenopausal osteoporosis. Lancet 2, 800-801 (1985).

26. Chu, J., Schweed, A. I., and Weiss, N. S. Survival among women with endometrial cancer: A comparison of estrogen users and nonusers. Amer. J. Obstet. Gynecol. 143, 569-573 (1982).

27. Cowan, L. D., Gordis, L., Tonascia, J. A., and Jones, G. S. Breast cancer incidence in women with a history of progesterone deficiency. Amer. J. Epidemiol. 114, 209-217 (1981).

28. Crilly, R. G., Marshall, D. H., and Nordin, B. E. C. The effect of oestradiol valerate and cyclic oestradiol valerate/DL-norgestrel on calcium metaboïsm. Postgrad. Med. J. 54 (Suppl. 2), 47-49 (1978).

29. Dequeker, J., and De Muylder, E. Long-term progestogen treatment and bone remodelling in peri-menopausal women: A longitudinal study. Maturitas 4, 309-313 (1982).

30. Eaker, E. D., and Castelli, W. P. Differential risk for coronary heart disease among women in the Framingham study, in "Coronary Heart Disease in Women" (E. Eaker, B. Packard, N. Wenger, T. Clarkson, H. A. Tyroler, Eds.) Haymarket Doyle, New York, 1987.

31. Ernster, V. L., and Cummings, S. R. Progesterone and breast cancer. Obstet. Gynecol. 68, 715-717 (1986).

32. Ettinger, B., Genant, H. K., and Cann, C. E. Long-term estrogen therapy prevents bone loss and fractures. Ann. Int. Med. 102, 319-324 (1985).

33. Ferenczy, A. How progestogens effect endometrial hyperplasia and neoplasia. Contemp. Obstet. Gyn. 11, 137-143 (1978).

34. Fremont-Smith, M., Meigs, J. V., Graham, R. M., and Gilbert, H. H. Cancer of endometrium and prolonged estrogen therapy. JAMA 131, 805-808 (1946).

35. Gambrell, R. D., Jr. Proposal to decrease the risk and improve the prognosis of breast cancer. Amer. J. Obstet. Gynecol. 150, 119-132 (1984).

36. Gambrell, R. D., Jr., Bagnell, C. A., and Greenblatt, R. B. Role of estrogens and progesterone in the etiology and prevention of endometrial cancer: Review. Amer. J. Obstet. Gynecol. 146, 696-707 (1983).

37. Gambrell, R. D., Maier, R. C., and Sanders, B. I. Decreased incidence of breast cancer in postmenopausal estrogen-progestogen users. Obstet. Gynecol. 62, 435-443 (1983).

38. Genant, H. K., Cann, C. E., Ettinger, B., and Gordon, G. S. Quantitative computed tomography of vertebral spongiosa: A sensitive method for detecting early bone loss after oophorectomy. Ann. Intern. Med. 97, 699-705 (1982).

39. Gordon, G. S., Picchi, J., and Roof, B. S. Antifracture efficacy of long-term estrogens for osteoporosis. Trans. Assoc. Amer. Physicians 86, 326-332 (1973).

40. Gorski, J., and Raher, B. Estrogen action in the uterus: The requisite for sustained estrogen binding in the nucleus. Gynecol. Oncol. 2, 249-258 (1974).

41. Gray, L. A., Chistropherson, W. M., and Hoover, R. N. Estrogens and endometrial carcinoma. Obstet. Gynecol. 49, 385-389 (1977).

42. Gusberg, S. B., and Kaplan, A. L. Precursors of corpus cancer. IV. Adenomatous hyperplasia as stage 0 carcinoma of the endometrium. Amer. J. Obstet. Gynecol. 87, 662-678 (1963).

43. Gusberg, S. B., and Kardon, P. Proliferative endometrial response to thecagranulosa cell tumors. Amer. J. Obstet. Gynecol. 111, 633-643 (1971).

44. Gusberg, S. B., Moore, D. B., and Martin, F. Precursors of corpus cancer. 2. A clinical and pathological study of adenomatous hyperplasia. Amer. J. Obstet. Gynecol. 68, 1472-1481 (1954).

45. Hammond, C. B., Jelovsek, F. R., Lee, K. L., Creasman, W. T., and Parker, R. T. Effects of long-term estrogen replacement therapy. I. Metabolic effects. Amer. J. Obstet. Gynecol. 133, 525-536 (1979). 
46. Hammond, C. B., and Soules, M. R. Endocrine aspects of adenocarcinoma of the endometrium in obstetrics and gynecology, in "Gynecology and Obstetrics" (J.J. Sciarra, Ed.), pp. 1-19. Harper and Row, New York, 1985.

47. Henderson, B. E., Ross, R. K., Paganini-Hill, A., and Mack, T. M. Estrogen use and cardiovascular disease. Amer. J. Obstet. Gynecol. 154, 1181-1186 (1986).

48. Hiatt, R. A., Bawol, R., Friedman, G. D., and Hoover, R. Exogenous estrogen and breast cancer after bilateral oophorectomy. Cancer 54, 139-144 (1984).

49. Hirvonen, E., Malkonen, M., and Manninen, V. Effects of different progestogens on lipoproteins during postmenopause replacement therapy. New Engl. I. Med. 304, 560-563 (1981).

50. Hoover, R., Glass A., Finkle, W. D., Azevedo, D., and Milne, K. Conjugated estrogens and breast cancer risk in women. J. Natl. Cancer Inst. 67, 815-820 (1981).

51. Hoover, R., Gray, L. A., Cole, P., and MacMahon, B. Menopausal estrogens and breast cancer. New Engl. J. Med. 295, 401-405 (1976).

52. Horsman, A., Gallagher, J. C., Simpson, M., and Nordin, B. E. Prospective trial of oestrogen and calcium in postmenopausal women. Brit. Med. J. 2, 789-792 (1977).

53. Horsman, A., Jones, M., Francis, R., and Nordin, C. The effect of estrogen dose on postmenopausal bone loss. New Engl. J. Med. 309, 1404-1407 (1983).

54. Hui, S. L., Wiske, P. S., Norton, J. A., and Johnston, C. C., Jr. A prospective study of change in bone mass with age in postmenopausal women. J. Chronic Dis. 35, 715-725 (1982).

55. Hulka, B. S. Breast cancer and exogenous estrogens. "Proceedings of the Symposium in Epidemiology and Health Risk Assessment," Columbia, MD, May 14-16, 1985. In press.

56. Hulka, B. S., Chambless, L. E., Deubner, D. C., and Wilkinson, W. E. Breast cancer and estrogen replacement therapy. Amer. J. Obstet. Gynecol. 143, 638-644 (1982).

57. Hulka, B. S., Fowler, W. C., Kaufman, D. G., Grimson, R. C., Greenberg, B. G., Hogue, C. J., Berger, G. S., and Pulliam, C. C. Estrogen and endometrial cancer: Cases and two control groups from North Carolina. Amer. J. Obstet. Gynecol. 137, 92-101 (1980).

58. Hulka, B. S., Kaufman, D. G., Fowler, W. C., Grimson, R. C., and Greenberg, B. G. Predominance of early endometrial cancers after long-term estrogen use. JAMA 244, 2419-2422 (1980).

59. Hutchinson, T. A., Polansky, S. M., and Feinstein, A. R. Postmenopausal oestrogens protect against fractures of hip and distal radius: A case-control study. Lancet 2, 705-709 (1979).

60. Jick, H., Dinan, B., and Rothman, K. J. Noncontraceptive estrogens and nonfatal myocardial infarction. JAMA 239, 1407-1408 (1978).

61. Johnson, R. E., and Specht, E. E. The risk of hip fracture in postmenopausal females with and without estrogen drug exposure. Amer. J. Public Health 71, 138-144 (1981).

62. Kaufman, D. W., Miller, D. R., Rosenberg, L., Helmrich, S. P., Stolley, P., Schottenfeld, D., and Shapiro, S. Noncontraceptive estrogen use and the risk of breast cancer. JAMA 252, 63-67 (1984).

63. Kay, C. R. Progestogens and arterial disease-Evidence from the Royal College of General Practitioners' study. Amer. J. Obstet. Gynecol. 142, 762-765 (1982).

64. Kelsey, J. L., Fischer, D. B., Holford, T. R., LiVolsi, V. A., Mostow, E. D., Goldenberg, I. S., and White, $C$. Exogenous estrogens and other factors in the epidemiology of breast cancer. $J$. Natl. Cancer Inst. 67, 327-333 (1981).

65. Kelsey, J. L., LiVolsi, V. A., Holford, T. R., and Fischer, D. B. A case-control study of cancer of the endometrium. Amer. J. Epidemiol. 116, 333-342 (1982).

66. Kennedy, D. L., Baum, C., and Forbes, M. B. Noncontraceptive estrogens and progestins: Use patterns over time. Obstet. Gynecol. 65, 441-446 (1985).

67. Kistner, R. W. The effects of progestational agents on hyperplasia and carcinoma in situ of the endometrium: A 10-year follow-up. Int. J. Gynecol. Obstet. 8, 561-572 (1970).

68. Kistner, R. W. Estrogens and endometrial cancer (editorial). Obstet. Gynecol. 48, 479-482 (1976).

69. Kontula, K. Progesterone-binding protein in human myometrium: Binding site concentration in relation to endogenous progesterone and estradiol levels. J. Steroid. Biochem. 6, 1555-1556 (1975).

70. Kreiger, N., Kelsey, J. L., Holford, T. R., and O'Connor, T. An epidemiologic study of hip fracture in postmenopausal women. Amer. J. Epidemiol. 116, 141-148 (1982). 
71. Krolner, B., and Nielsen, S. P. Bone mineral content of the lumbar spine in normal and osteoporotic women: Cross-sectional and longitudinal studies. Clin. Sci. 62, 329-336 (1982).

72. Kuusi, T., Tikkanen, M. J., Nikkila, E. A., and Sipinen, S. Progestagens and high-density lipoproteins (letter). Lancet 2, 1163 (1984).

73. Lafferty, F. W., and Helmuth, D. O. Postmenopausal estrogen replacement: The prevention of osteoporosis and systemic effects. Maturitas 7, 147-159 (1985).

74. LaRosa, J. C., Chambless, L. E., Criqui, M. H., Frantz, I. D., Glueck, C. J., Heiss, G., and Morrisson, J. A. Patterns of dyslipoproteinemia in selected North American populations: The Lipid Research Clinics Program Prevalence Study. Circulation 73, 112-129 (1986).

75. Lasagna, L., and Greenblot, D. J. More than skin deep: Transdermal drug-delivery systems. New Engl. J. Med. 314, 1638-1639 (1986).

76. La Vecchia, C., Decarli, A., Parazzini, F., Gentile, A., Liberati, C., and Franceschi, S. Noncontraceptive estrogens and the risk of breast cancer in women. Int. J. Cancer 38, 853-858 (1986).

77. Lee, N. C., and Rubin, G. L. Breast cancer in postmenopausal estrogen-progestogen users. Obstet. Gynecol. 64, 832-833 (1984).

78. Liang, A. P., Levenson, A. G., Layde, P. M., Shelton, J. D., Hatcher, R. A., Potts, M., and Michelson, M. J. Risk of breast, uterine corpus, and ovarian cancer in women receiving medroxyprogesterone injections. JAMA 249, 2909-2912 (1983).

79. Lindsay, R., Aitken, J. M., Anderson, J. B., Hart, D. M., MacDonald, E. B., and Clarke, A. C. Long-term prevention of postmenopausal osteoporosis by estrogen. Lancet 1, 1038-1041 (1976).

80. Lindsay, R., and Hart, D. M. Gonadal steroids and osteoporosis, in "Steroid Modulation of Neuroendocrine Function. Sterols, Steroids and Bone Metabolism" (L. Martini, G. S. Gordon, and F. Sciarra, Eds.). Excerpta Medica, New York, 1984.

81. Lindsay, R., Hart, D. M., Forrest, C., and Baird, C. Prevention of spinal osteoporosis in oophorectomized women. Lancet 2, 1151-1154 (1980).

82. Lindsay, R., Hart, D. M., McLean, A., Clark, A. C., Kraszewski, A., and Garwood, J. Bone response to termination of estrogen treatment. Lancet 1, 1325-1327 (1978).

83. Lindsay, R., Hart, D. M., Purdie, D., Ferguson, M. M., Clark, A. S., and Kraszewski, A. Comparative effects of oestrogen and a progestogen on bone loss in postmenopausal women. Clin. Sci. Mol. Med. 54, 193-195 (1978).

84. Lucas, W. E. Causal relationships between endocrine-metabolic variables in patients with endometrial carcinoma. Obstet. Gynecol. Survey 29, 507-528 (1974).

85. Mack, T. M., Pike, M. C., Henderson, B. E., and Pfeffer, R. I. Estrogens and endometrial cancer in a retirement community. New Engl. J. Med. 294, 1262-1267 (1976).

86. MacMahon, B. Cardiovascular disease and noncontraceptive oestrogen therapy, in "Coronary Heart Disease in Young Women" (M. F. Oliver, Ed.), pp. 197-207. Churchill Livingstone, New York, 1978.

87. Mattsson, L. A., and Samsioe, G. Estrogen-progestogen replacement in climacteric women, particularly as regards a new type of continuous regimen. Acta Obstet. Gynecol. Scand.130, 53-58 (1985).

88. Mazess, R. B. On aging bone loss. Clin. Orthop. 165, 239-252 (1982).

89. McCarty, K. S., Jr. Steroid hormone receptors in the regulation of differentiation. A review. Amer. J. Pathol. 86, 705-744 (1977).

90. McDonald, T. W., Annegers, J. F., O'Fallon, W. M., and Dockerty, M. B. Exogenous estrogen and endometrial carcinoma: Case-control and incidence study. Amer. J. Obstet. Gynecol.127, 572-580 (1977).

91. Meade, T. W., Greenberg, G., and Thompson, S. G. Progestogens and cardiovascular reactions associated with oral contraceptives and a comparison of the safety of 50- and 30- $\mu \mathrm{g}$ preparations. Brit. Med. J. 280, 1157-1161 (1980).

92. Meyer, F., Brown, J. B., Morrison, A. S., and MacMahon, B. Endogenous sex hormones, prolactin, and breast cancer in premenopausal women. $J$. Natl. Cancer Inst. 77, 613-616 (1986).

93. Nachtigall, L. E., Nachtigall, R. H., Nachtigall, R. D., and Beckman, E. M. Estrogen replace- 
ment therapy. I. A 10-year prospective study in the relationship to osteoporosis. Obstet. Gynecol. 53, 277-281 (1979).

94. Nachtigall, L. E., Nachtigall, R. H., Nachtigall, R. D., and Beckman, E. M. Estrogen replacement therapy. II. A prospective study in the relationship to carcinoma and cardiovascular and metabolic problems. Obstet. Gynecol. 54, 74-79 (1979).

95. National Cancer Institute. "1986 Annual Cancer Statistics Review." (E. J. Sondik, J. L. Young, J. W. Horn, L. A. Gloeckler-Ries, Eds.) National Cancer Institute, December 1986. USPHS, Bethesda, MD.

96. Newton-John, H. F., and Morgan, D. B. The loss of bone with age, osteoporosis and fractures. Clin. Orthop. 71, 229-252 (1970).

97. Notelovitz, M., Gudat, J. C., Ware, M. D., and Dougherty, M. C. Oestrogen-progestin therapy and the lipid balance of post-menopausal women. Maturitas 54, 301-308 (1982).

98. Ottosson, U. B. Oral progesterone and estrogen/progestogen therapy. Acta Obstet. Gynecol. Scand. 127, 5-37 (1984).

99. Ottosson, U. B., Johansson, B. G., and von Schoultz, B. Subfractions of high-density lipoprotein cholesterol during estrogen replacement therapy: A comparison between progestogens and natural progesterone. Amer. J. Obstet. Gynecol. 151, 746-750 (1985).

100. Paganini-Hill, A., Ross, R. K., Gerkins, V. R., Henderson, B. E., Arthur, M., and Mack, T. M. Menopausal estrogen therapy and hip fractures. Ann. Intern. Med. 95, 28-31 (1981).

101. Paterson, M. E. L., Wade-Evans, T., Sturdee, D. W., Thom, M. H., and Studd, J. W. W. Endometrial disease afer treatment with oestrogens and progestogens in the climacteric. Brit. Med. J. 280, 822-824 (1980).

102. Petitti, D. B., Perlman, J. A., and Sidney, S. Postmenopausal estrogen use and heart disease. New Engl. J. Med. 315, 131-132 (1986).

103. Pfeffer, R. I., Whipper, G. H., Kurosaki, T. T., and Chapman, J. M. Coronary risk and estrogen use in postmenopausal women. Amer. J. Epidemiol. 107, $479-487$ (1978).

104. Pike, M. C., Henderson, B. E., Krailo, M. D., Duke, A., and Roy, S. Breast cancer in young women and use of oral contraceptives: Possible modifying effect of formulation and age at use. Lancet 2, 926-930 (1983).

105. Potocki, J. Wplyw leczenia estrogenami na niewydolnosc wiencowa u kobiet po menopauzie. Pol. Tyg. Lek. 26, 1812-1815 (1971).

106. Read, G. F., Bradley, J. A., Wilson, D. W., George, W. D., and Griffiths, K. Evaluation of luteal-phase salivary progesterone levels in women with benign breast disease or primary breast cancer. Eur. J. Cancer Clin. Oncol. 21, 9-17 (1985).

107. Recker, R. R., Saville, P. D., and Heany, R. P. Effect of estrogens and calcium carbonate on bone loss in postmenopausal women. Ann. Intern. Med. 87, 649-655 (1977).

108. Reifenstein, E. C. The treatment of advanced endometrial cancer with hydroxyprogesterone caproate. Gynecol. Oncol. 2, 377-414 (1974).

109. Riggs, B. L., Seeman, E., Hodgson, S. F., Taves, D. R., and O'Fallon, W. M. Effect of the fluoride/calcium regimen on vertebral fracture occurrence in postmenopausal osteoporosis. New Engl. J. Med. 306, 446-450 (1982).

110. Robin, J. C., Ambrus, J. L., and Ambrus, C. M. Studies on osteoporosis. X. Effect of estrogenprogestin combination on heparin-induced osteoporosis. Steroids 42, 669-675 (1983).

111. Robinson, R. W., Higano, N., and Cohen, W. D. Effects of long-term administration of estrogens on serum lipids of postmenopausal women. New Engl. J. Med. 86, 597-607 (1977).

112. Ron, E., Lunenfeld, B., Menczer, J., Blumstein, T., Katz, L., Oelsner, G., and Serr, D. Cancer incidence in a cohort of infertile women. Amer. J. Epidemiol. 125, 780-790, 1987.

113. Rosenberg, L., Armstrong, B., and Jick, H. Myocardial infarction and estrogen therapy in postmenopausal women. New Engl. J. Med. 294, 1256-1259 (1976).

114. Rosenberg, L., Stone, D., Shapiro, S., Kaufman, P., Stolley, P. D., and Miettinen, O. S. Noncontraceptive estrogens and myocardial infarction in young women. JAMA 244, 339-342 (1980).

115. Ross, R. K., Paganini-Hill, A., Gerkins, V. R., Mack, T. M., Pfeffer, R., Arthur, M., and Henderson, B. E. A case-control study of menopausal estrogen therapy and breast canccr. JAMA 243, 1635-1639 (1980). 
116. Ross, R. K., Paganini-Hill, A., Mack, T. M., Arthur, M., and Henderson, B. E. Menopausal estrogen therapy and protection from death from ischaemic heart disease. Lancet $1,858-860$ (1981).

117. Schottenfeld, D. Cancer risks of medical treatment. Cancer J. Clin. 32, 4-25 (1982).

118. Secreto, G., Toniolo, P., Berrino, F., Recchione, C., De Pietro, S., Fariselli, G., and Decarli, A. Increased androgenic activity and breast cancer risk in premenopausal women. Cancer Res. 44, 5902-5905 (1984).

119. Selby, P. L., Peacock, M., Barkworth, S. A., Brown, W. B., and Taylor, G. A. Early effects of ethinyloestradiol and norethisterone treatment in postmenopausal women on bone resorption and calcium regulating hormones. Clin. Sci. 69, 265-271 (1985).

120. Shapiro, S., Kaufman, D. W., Slone, D., and Rosenberg, L. Recent and past use of conjugated estrogens in relation to adenocarcinoma of the endometrium. New Engl.J. Med. 303, 485-489 (1980).

121. Shapiro, S., Kelly, J. P., Rosenberg, L., Kaufman, D. W., Helmrich, S. P., Rosenshein, N. B., Lewis, J. L., Jr., Knapp, R. C., Stolley, P. D., and Schottenfeld, D. Risk of localized and widespread endometrial cancer in relation to recent and discontinued use of conjugated estrogens. New Engl. J. Med. 313, 969-972 (1985).

122. Sherman, B. M., Wallace, R. B., and Bean, J. A. Cyclic ovarian function and breast cancer. Cancer Res. 42, 3286s-3288s (1982).

123. Silfverstolpe, G., Gustafson, A., Samsioe, G., and Svanborg, A. Lipid metabolic studies in oophorectomized women: Effects on serum lipids and lipoproteins of three synthetic progestogens. Maturitas 4, 103-111 (1982).

124. Smith, D. C., Prentice, R., Thompson, D. J., and Herrmann, W. L. Association of exogenous estrogen and endometrial carcinoma. New Engl. J. Med. 293, 1164-1167 (1975).

125. Somers, S. C. Carcinoma of the endometrium, in "The Uterıs" (N. J. Norris, A. T. Hertig, and M. R. Abell, Eds.), p. 277. Williams and Wilkins, Baltimore, 1973.

126. Sowers, M. R., Wallace, R. B., and Lemke, J. H. Correlates of mid-radius bone density among postmenopausal women: A community study. Amer. J. Clin. Nutr. 41, 1045-1053 (1985).

127. Spellacy, W. N., Buhi, W. C., and Birk, S. A. The effects of norgestrel on carbohydrate and lipid metabolism over one year. Amer. J. Obstet. Gynecol. 125, 984-986, 1976.

128. Spellacy, W. N., Newton, R. E., Buhi, W. C., and Birk, S. A. Lipid and carbohydrate metabolic studies after one year of megestrol acetate treatment. Fertil. Steril. 27, 157-161 (1976).

129. Spengler, R. F., Clarke, E. A., Woolever, C. A., Newman, A. M., and Osborn, R. W. Exogenous estrogens and endometrial cancer: A case-control study and assessment of potential biases. Amer. J. Epidemiol. 114, 497-506 (1981).

130. Stadel, B. V., and Schlesselman, J. J. Oral contraceptive use and the risk of breast cancer in women with a "prior" history of benign breast disease. Amer. J. Epidemiol. 123, 373-382 (1986).

131. Stampfer, M. J., Willett, W. C., Colditz, G. A., Rosner, B., Speizer, F. E., and Hennekens, C. H. A prospective study of postmenopausal estrogen therapy and coronary heart disease. New Engl. J. Med. 313, 1044-1049 (1985).

132. Sturtevant, F. M. Breast cancer and oral contraceptives: Critique of the proposition that high potency progestogen products confer excess risk. Biomed. Pharmacother. 38, 371-379 (1984).

133. Szklo, M., Tonascia, J., Gordis, L., and Bloom, I. Estrogen use and myocardial infarction risk: A case-control study. Prev. Med. 13, 510-516 (1984).

134. Talbott, E., Kuller, L. H., and Detre, K. Biologic and psychosocial risk factors of sudden death from coronary disease in white women. Amer. J. Cardiol. 39, 858-864 (1977).

135. Thom, M. H., White, P. J., Williams, R. M., Sturdee, D. W., Paterson, M. E. L., Wade-Evans, T., and Studd, J. W. W. Prevention and treatment of endometrial disease in climacteric women receiving estrogen therapy. Lancet, 2, 455-457 (1979).

136. Thomas, D. B., Persing, J. P., and Hutchinson, W. B. Exogenous estrogens and other risk factors for breast cancer in women with benign breast diseases. J. Natl. Cancer Inst. 69, 1017-1025 (1982).

137. Tikkanen, M. J., and Nikkila, E. A. Natural oestrogen as an effective treatment for type-II hyperlipoproteinaemia in postmenopausal women. Lancet 2, 490-491 (1978). 
138. Tikkanen, M. J., Nikkila, E. A., Kuusi, T., and Sipinen, S. Different effects of two progestins on plasma high density lipoprotein (HDL) and postheparin plasma hepatic lipase activity. Atherosclerosis 40, 365-369 (1981).

139. U.S. Department of Health and Human Services. "Cancer Incidence and Mortality in the United States, SEER 1973-81." NIH Publication No. 85-1837, 1984.

140. U.S. Department of Health and Human Services, "Vital Statistics of the United States, 1981. Vol. 2-Mortality (Part A)." National Center for Health Statistics, Hyattsville, MD, 1986.

141. Vilska, S., Punnonen, R., and Rauramo, L. Long-term postmenopausal hormone therapy and serum HDL-C, total cholesterol and triglycerides. Maturitas 5, 97-104 (1983).

142. Wahl, P., Walden, C., Knopp, R., Hoover, J., Wallace, R., Heiss, G., and Rifkind, B. Effect of estrogen/progestin potency on lipid/lipoprotein cholesterol. New Engl. J. Med. 308, 862-867 (1983).

143. Walker, A. M., and Jick, H. Declining rates of endometrial cancer. Obstet. Gynecol. 56, 733-736 (1980).

144. Wallentin, L., and Larsson-Cohn, V. Metabolic and hormonal effects of postmenopausal oestrogen replacement therapy. II. Plasma lipids. Acta Endocrinol. (Copenhagen) 86, 597-607 (1977).

145. Weiss, N. S., Szekely, D. R., and Austin, D. F. Increasing incidence of endometrial cancer in the United States. New Engl. J. Med. 294, 1259-1262 (1976).

146. Weiss, N. S., Szekely, D. R., English, D. R., and Schweid, A. I. Endometrial cancer in relation to patterns of menopausal estrogen use. JAMA 242, 261-264 (1979).

147. Weiss, N. S., Ure, C. L., Ballard, J. H., Williams, A. R., and Daling, J. R. Decreased risk of fractures of the hip and lower forearm with postmenopausal use of estrogen. New Engl. J. Med. 303, 1195-1198 (1980).

148. Wentz, W. B. Progestin therapy in endometrial hyperplasia. Gynecol. Oncol. 2, 362-367 (1974).

149. Wilson, P. W., Garrison, R. J., and Castelli, W. P. Postmenopausal estrogen use, cigarette smoking, and cardiovascular morbidity in women over 50. The Framingham Study. New Engl. J. Med. 313, 1038-1043 (1985).

150. Wingo, P. A., Layde, P. M., Lee, N. C., Rubin, G., Ory, H. W. The risk of breast cancer in postmenopausal women who have used estrogen. JAMA 257, 209-215 (1987).

151. Wingo, P. A., Layde, P. M., Webster, L. A., and Ory, H. W. "Risk of Breast Cancer in Women using Postmenopausal Estrogens." Presented at the meeting of the American College of Obstetrics and Gynecology, Atlanta, GA, May 1983.

152. World Health Organization. Collaborative study of neoplasia and steroid contraceptives. Breast cancer, cervical cancer, and depot medroxyprogesterone acetate. Lancet, 2, 1207-1208 (1984).

153. Wren, B., and Garrett, D. The effect of low-dose piperazine oestrone sulphate and low-dose levonorgestrel on blood lipid levels in post-menopausal women. Maturitas, 7, 141-146 (1985).

154. Ziel, H. K., and Finkle, W. D. Increased risk of endometrial carcinoma among users of conjugated estrogens. New Engl. J. Med. 293, 1167-1170 (1975). 